\title{
Numerical Investigation of the Physical Properties Effect on the Thermal Performance of a Vertical Geothermal Heat Exchanger
}

\author{
M. Benyoub \\ Laboratory of Applied Biomechanics and Biomaterials \\ Department of Mechanical Engineering \\ ENP Oran, Algeria \\ tafsou3003@yahoo.fr \\ B. Bouhacina \\ Energetic and Applied Thermal Laboratory (ETAP) \\ Faculty of Technology, University of Tlemcen \\ Algeria \\ bouhacina_b@yahoo.fr
}

\author{
B. Aour \\ Laboratory of Applied Biomechanics and Biomaterials \\ Department of Mechanical Engineering \\ ENP Oran, Algeria \\ ben_aour@yahoo.fr \\ K. Sadek \\ Laboratory of Applied Biomechanics and Biomaterials \\ Department of Mechanical Engineering \\ ENP Oran, Algeria \\ Sadekkaddour@gmail.com
}

\begin{abstract}
Low-temperature geothermal energy is a promising technique for heating and cooling residential and commercial premises, especially since it is one of the green energy solutions that respect the environment. The principle of this technique is based on thermal exchange between the heat pump and the basement using a vertically buried heat exchanger. This is usually made of a $\mathrm{U}$-shaped tube inserted vertically in a borehole made in the ground and filled with a filler material. The purpose of the present study is to vary the different construction materials of the U-tube, the filling material and the soil, in order to obtain the most energy-efficient parameters. The evolution of temperature and heat flux as a function of time has been highlighted for different combinations. Knowing that an experimental study requires a considerable monetary fund, the present model has been validated using previously literature results. Recommendations on the choice of different materials of the geothermal heat exchanger are proclaimed at the end of this work.
\end{abstract}

Keywords-geothermal energy; heat exchanger; finite volumes; temperature; heat flux

\section{INTRODUCTION}

Seasonal storage systems of solar energy by geothermal well (SSGW) that use the ground as a heat source is a promising and highly efficient renewable energy technology to provide heating and cooling of residential and commercial buildings and sanitary hot water $[1,2]$. This system is generally composed of a heat pump, a solar thermal panel, a geothermal heat exchanger and a system for heat distribution in the building (radiators or heating floor), see Figure 1. These systems offer better levels of comfort, reasonable environmental safety, reduced greenhouse gas emissions and reduced noise levels [3]. In an area between 5 and 45 meters deep, the soil is at a constant temperature throughout the year: warmer than the ambient temperature in winter and cooler in summer [4]. The geothermal heat pump allows to collect heat from the building and to inject it into the ground during the summer and to transfer the heat stored in the ground to the building during the winter [5]. The system uses the ground as a heat source when operating in heating mode while in cooling mode, it uses the soil as a heat sink [1]. Currently, the SSGW is a high-performance and economical technology for heating and cooling buildings. Most geothermal heat pumps use vertical buried heat exchangers. They offer better energy performance compared to horizontal heat exchangers because of the small temperature fluctuations generated in the ground.

All geothermal heat exchangers (GHEs) generally consist of a U-tube pipe disposed in a known deep borehole. The boreholes have typical diameters ranged from $76 \mathrm{~mm}$ to $127 \mathrm{~mm}$ filled with a high thermal conductivity bentonite grout in order to ensure a good heat transfer between the fluid and the stock. The fluid enters the probe at a known temperature, the pipe diameter is in the range of $19 \mathrm{~mm}$ to $38 \mathrm{~mm}$. The upper surface of the geothermal heat exchanger is free and in constant contact with the atmosphere [6]. Several works have been conducted to deal with the problem of heat transfer in the soil. Analytical models are typically based on the theory of the source line [7] or the cylindrical source [8]. These two models assume a source of infinite length in an isotropic medium, and they do not take into account the variation of the temperature at depth and the surface effects such as radiation and convection. On the other hand, several numerical and experimental studies have treated the vertical geothermal heat exchangers. Author in [9] has studied the problem of the thermal response of a multiple geothermal probes heat exchanger subjected to various conditions. Authors in [10] developed a numerical model based 
on an explicit finite difference technique to simulate the heat transfer conditions of a geothermal probe with a U-tube. Authors in [11] carried out a two-dimensional transient model by finite elements to study thermal interference between the Utubes. Authors in [12] developed an equivalent diameter model for a unique borehole with a U-tube inside. Authors in [13] proposed a three-dimensional implicit finite difference method with a rectangular coordinate system. The similar meshing technique was used in [14]. Authors in [15] developed a threedimensional unstructured finite volumes model for a unique borehole. The simulation with this model is effective for Utube geothermal heat exchangers.

In [16], authors proposed an improved finite element model where the well is reduced to a one-dimensional system where the U-shaped loop is replaced by a single pipe of equivalent diameter. Authors in [17] presented an analytical solution to calculate borehole fluid temperatures for time-scales from minutes to decades. Authors in [18] compared different existing approaches for calculating the thermal resistance of the borehole, including the thermal short circuit between the pipes. They also performed a 3D numerical simulation of a drilling well in standard unique U-tube. In [19], authors examined the effects of axial thermal conduction by comparing the results obtained using the finite and infinite linear sources method. Authors in [20] studied the variation of temperature and thermal flux of the borehole wall as a function of time in order to describe the turbulent phenomenon inside the U-tube and to show the temperature distribution in and around the U- tube. Authors in [21] have numerically studied the effect of U-tube diameter, Reynolds number and tube connection configurations on the thermal performance of vertical geothermal heat exchangers. Authors in [22] developed an iterative algorithm to evaluate the thermal performance of GHE by coupling both formulas to calculate the heat transfer rate. The objective of this work is to highlight the effects of flow velocity and materials properties of U-tube, concrete grout and soil on the performance of a geothermal heat exchanger.

\section{MATHEMATICAL FORMULATION}

The differential equations presented in this paper describe the principle of mass conservation of momentum and energy. In what follows, we will present the formulation describing the phenomenon of forced convection inside the cylindrical pipe and the thermal conduction inside solid media. The discretization of the three-dimensional differential equations of the unsteady flow equation is performed using the finite volume method based on the Fujun algorithm [23]. The differential conservation equations expressed as a function of the different variables of the flow ( $\mathrm{u}, \mathrm{v}, \mathrm{w}, \mathrm{k}, \varepsilon$ and $\mathrm{T}$ ) can be written in the following general form [24].

- In vector rotation:

$$
\frac{\partial}{\partial t}(\rho \phi)+\operatorname{div}(\rho \cdot U \cdot \phi)=\operatorname{div}\left(\Gamma_{\phi} \cdot \operatorname{grad} \phi\right)+S_{\phi}
$$

- In tensor rotation:

$$
\frac{\partial}{\partial t}(\rho \phi)+\frac{\partial}{\partial x_{j}}(\rho \cdot U \cdot \phi)=\frac{\partial}{\partial x_{j}} \cdot\left(\Gamma_{\phi} \cdot \frac{\partial}{\partial x_{j}}\right)+S_{\phi}
$$

where $\frac{\partial}{\partial t}(\rho \phi)$ is the foreign exchange rate or accumulation, $\frac{\partial}{\partial x_{j}}(\rho \cdot U \cdot \phi)$ the convection flux and $\frac{\partial}{\partial x_{j}} \cdot\left(\Gamma_{\phi} \cdot \frac{\partial \phi}{\partial x_{j}}\right)$ the diffusion flux. The differential equation describing conservation of momentum for a Newtonian fluid flow is written as:

$$
\rho\left(\frac{\partial U_{i}}{\partial t}+U_{J} \frac{\partial U_{i}}{\partial x_{j}}\right)=-\frac{\partial P}{\partial x_{j}}+\beta_{i}+\mu\left(\frac{\partial}{\partial x_{j}}\left(\frac{\partial U_{i}}{\partial x_{j}}+\frac{\partial U_{j}}{\partial x_{i}}\right)\right)
$$

The equation of motion in the $\mathrm{x}$ direction is written in the following form:

$$
\frac{\partial}{\partial t}(\rho \cdot U)+\operatorname{div}(\rho \cdot U \cdot U)=\operatorname{div}(\mu \cdot \overrightarrow{\operatorname{grad} U})-\frac{\partial \mathrm{P}}{\partial x}+B_{x}
$$

The differential equation describing the principle of conservation of mass is:

$$
\frac{\partial}{\partial t} \rho+\frac{\partial}{\partial x}(\rho \cdot u)+\frac{\partial}{\partial y}(\rho \cdot v)+\frac{\partial}{\partial z}(\rho \cdot w)=0
$$

Two transport equations in the k- $\varepsilon$ model are used, (6) for the kinetic energy of turbulence $\mathrm{k}$ obtained from an exact equation and (7) for the rate of kinetic energy dissipation $\varepsilon$ obtained by physical resonance.

$$
\begin{aligned}
& \frac{\partial}{\partial t}(\rho k)+\frac{\partial}{\partial x_{i}}\left(\rho \cdot k \cdot U_{i}\right)= \\
& \frac{\partial}{\partial x_{j}}\left(\left(\mu+\frac{\mu_{t}}{\sigma_{k}}\right) \frac{\partial k}{\partial x_{j}}\right)+G_{k}+G_{b}-\rho \varepsilon+S_{k} \\
& \frac{\partial}{\partial t}(\rho \varepsilon)+\frac{\partial}{\partial x_{i}}\left(\rho \cdot \varepsilon \cdot U_{i}\right)= \\
& \frac{\partial}{\partial x_{j}}\left(\left(\mu+\frac{\mu_{t}}{\sigma_{\varepsilon}}\right) \frac{\partial \varepsilon}{\partial x_{j}}\right) \\
& +\left(C_{1 \varepsilon} \frac{\varepsilon}{\kappa}\left(G_{\kappa}+C_{3 \varepsilon} G_{b}\right)\right)-C_{2 \varepsilon} \rho \frac{\varepsilon^{2}}{\kappa}+S_{\varepsilon}
\end{aligned}
$$

where $\sigma_{k}$ and $\sigma_{\varepsilon}$ are the Prandtl numbers of $\kappa$ and $\varepsilon$ with values of 1.0 and 1.2 respectively. $S_{k}$ and $S_{\varepsilon}$ are the terms source, $C_{1 \varepsilon}, C_{2 \varepsilon}$ and $C_{3 \varepsilon}$ are empirical constants (in this case $C_{1 \varepsilon}=C_{3 \varepsilon}=1.44, C_{2 \varepsilon}=1.92$ ) $[25,27]$. The turbulent viscosity is given by:

$$
\mu_{t}=\rho C_{\mu} \frac{k^{2}}{\varepsilon}
$$

where $C_{\mu}=0.09$.

The energy equation contains a large number of influencing parameters. Taking as simplifying hypothesis chosen in the 
elaboration of our numerical model the form of the equation where $\rho$ and $\lambda$ (thermal conductivity coefficient) are constant. For the unsteady flow where the viscous dissipation is neglected the equation is written as:

$$
\operatorname{div}(\rho \cdot U \cdot h)=\operatorname{div}(\lambda \cdot \overrightarrow{\operatorname{grad}} T)+S_{h}
$$

The boundary conditions at the interface are imposed simultaneously in the fluid and solid domains. According to the Fourier law of conductive heat transfer, the term $\operatorname{div}(\lambda \overrightarrow{\operatorname{grad}} T)$ represents the influence of heat by conduction in the flow. For ideal gases and for solids and liquids one can write:

$$
C_{p} \cdot \overrightarrow{\operatorname{grad}} T=\overrightarrow{\operatorname{grad}} h
$$

In our case where $C_{P}$ is constant, the relationship $h=f(t)$ is

$$
h=C_{p} \cdot T
$$

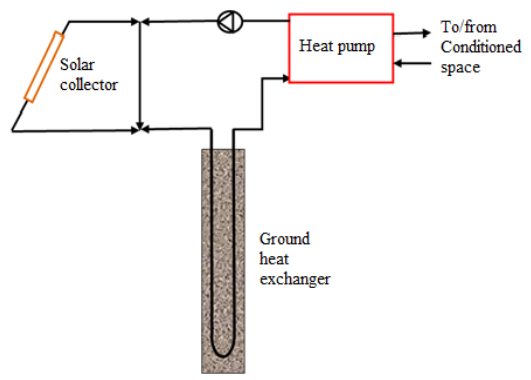

Fig. 1. Schematic diagram of ground-coupled heat pump (GCHP) system with solar collector.

\section{NUMERICAL PROCEDURE}

\section{A. Resolution Method}

In general, the method for solving the problem of fluid mechanics or heat transfer follows the procedure illustrated by the flowchart in Figure 2. It can be carried out in three steps:

1. Construction of the geometric model and mesh using the Gambit software.

2. Input of boundary conditions and material properties and resolution of equations using Fluent software.

3. Post-processing of the obtained results.

\section{B. Model of Validation}

In order to validate the studied model, we used in a first approach the same model with [28] (see Figure 3). The geometry analyzed is a $5 \mathrm{~m}$ slice of a geothermal heat exchanger (GHE) inserted into a borehole. It consists of a single U-tube $0.11 \mathrm{~m}$ in diameter. The model shown in Figure 3 includes three main areas: tube, grout and natural soil. Model construction is done using Gambit software while numerical simulations are performed by Fluent software.

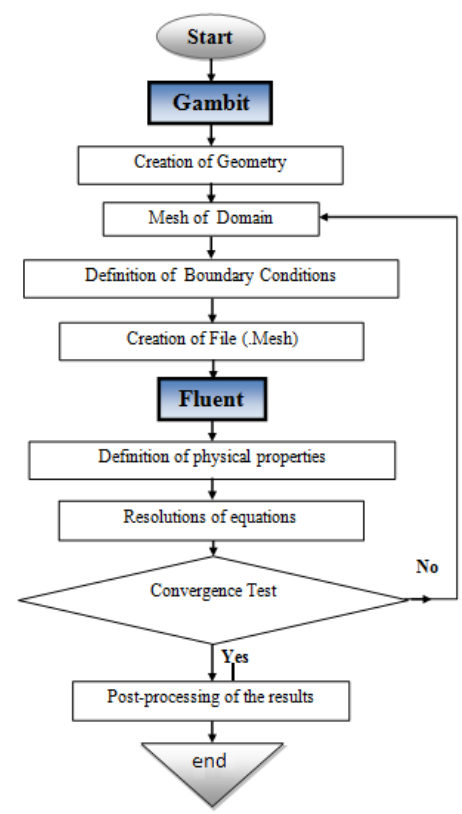

Fig. 2. Flowchart illustrating the steps of the geothermal heat exchanger modeling.

\section{Geometric and Thermal Parameters}

The parameters determining the geometric and thermal characteristics of the GHE are given in Table I. A time step of $1 \mathrm{~h}$ has been taken a heat storage time of $700 \mathrm{~h}$.

TABLE I. GEOMETRIC AND THERMAL CHARACTERISTICS OF THE GHE

\begin{tabular}{|c|c|c|}
\hline Parameter & Value & Unity \\
\hline Drilling diameter & 0.110 & $\mathrm{~m}$ \\
\hline Outside diameter of U pipes & 0.032 & $\mathrm{~m}$ \\
\hline Distance between pipe centers & 0.060 & $\mathrm{~m}$ \\
\hline No of pipes in the borehole & 2 & \\
\hline Conductivity of the soil & 3.5 & $\mathrm{~W} / \mathrm{mK}$ \\
\hline Conductivity of the grout & 1.3 & $\mathrm{~W} / \mathrm{mK}$ \\
\hline Diffusivity of the soil & $1.62 \times 10-6$ & $\mathrm{~m}^{2} / \mathrm{s}$ \\
\hline Diffusivity of the grout & $3.33 \times 10-7$ & $\mathrm{~m}^{2} / \mathrm{s}$ \\
\hline
\end{tabular}

\section{Physical Parametres}

Soil and upper soil surface temperatures as well as the flux density imposed in [28] on the two pipe lugs are entered as calculation input data whose temperature is $10^{\circ} \mathrm{C}$ and the flux density is $300 \mathrm{~W} / \mathrm{m}^{2}$. The thermo-physical properties $(\mathrm{Cp}, \mu, \mathrm{k}$, $\rho$ et Tin) of the fluid and solids are considered constants. The physical parameters of the materials considered for the validation of our model are presented in Table II.

\begin{tabular}{|c|c|c|c|}
\hline Materials & $\begin{array}{c}\text { Thermal } \\
\text { conductivity } \\
\left(\mathbf{W} / \mathbf{m}^{\circ} \mathbf{K}\right)\end{array}$ & $\begin{array}{c}\text { Density } \\
(\mathrm{Kg} / \mathrm{m3})\end{array}$ & $\begin{array}{c}\text { Specific heat } \\
\text { capacity } \\
\left(\mathrm{J} / \mathrm{Kg}^{\circ} \mathrm{K}\right)\end{array}$ \\
\hline Soil & 3.5 & 2360 & 915 \\
\hline Grout (concrete) & 1.3 & 2500 & 1561 \\
\hline U-tube (HDPE) & 0.48 & 1100 & 1465 \\
\hline
\end{tabular}

TABLE II. PHYSICAL PROPERTIES OF THE MATERIALS USED FOR THE 5M SLICE OF THE GEOTHERMAL HEAT EXCHANGER. 


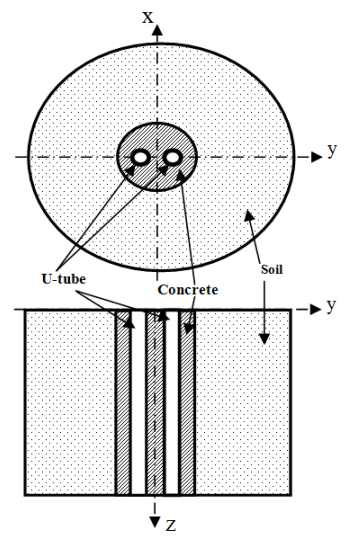

Fig. 3. Schematic diagram of a section of $5 \mathrm{~m}$ of the validation model.

\section{E. Study of Mesh Sensitivity and Validation}

In order to study the mesh sensitivity and validate our numerical model, three tests with different meshes were carried out. Figure 4 shows the selected mesh (mesh 3 ). The results obtained from the evolution of the concrete wall temperature as a function of time were compared with the numerical and analytical results of [28] as shown in Figure 4. Maximum temperatures obtained for each mesh are as follows: mesh 1: $293.72^{\circ} \mathrm{K}$, mesh 2: $293.85^{\circ} \mathrm{K}$, mesh 3: $294.04^{\circ} \mathrm{K}$, while the result obtained in [28] is $294^{\circ} \mathrm{K}$. Therefore, we can notice that the closest to [28] result is the one obtained by the mesh 3 and consequently, this one will be used for the numerical simulation of the geothermal vertical U-tube heat exchanger. Figure 5 shows the evolution of the temperature of the concrete wall as a function of time. It can be seen that the curve obtained by the numerical model developed is in good agreement with that obtained analytically and numerically in [28]. In fact, the temperature of the concrete wall increases from $10^{\circ} \mathrm{C}\left(283^{\circ} \mathrm{K}\right)$ to $21^{\circ} \mathrm{C}\left(294^{\circ} \mathrm{K}\right)$ after $700 \mathrm{~h}$.

\section{NUMERICAL MODELING OF THE STUDIED GHE}

\section{A. Geometrical Configuration}

The geometrical configuration of the studied model of GHE is presented in Figure 6. It consists of U-tube with $32 \mathrm{~mm}$ diameter, $0.06 \mathrm{~m}$ distance between its two legs, fixed via concrete vertically inside the borehole of $0.11 \mathrm{~m}$ diameter and depth of $8 \mathrm{~m}$. The diameter of the surrounding soil is $6 \mathrm{~m}$ and the depth is $8 \mathrm{~m}$.

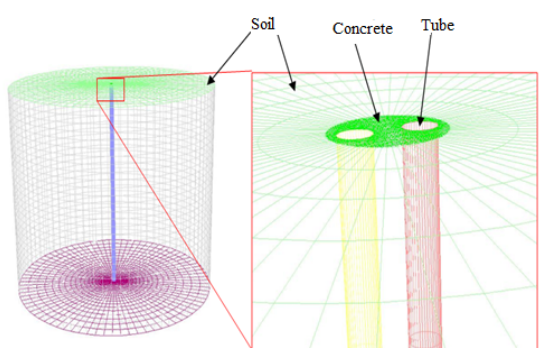

Fig. 4. Numerical mesh used for the validation model

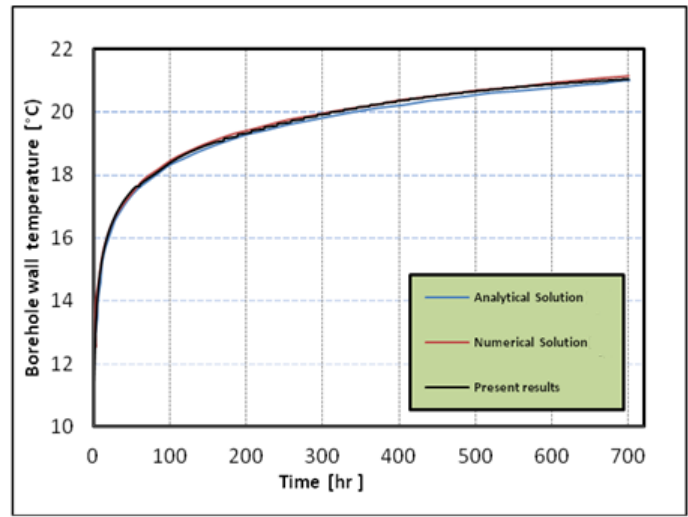

Fig. 5. Comparison of the results obtained for the evolution of the concrete wall temperature as a function of time.

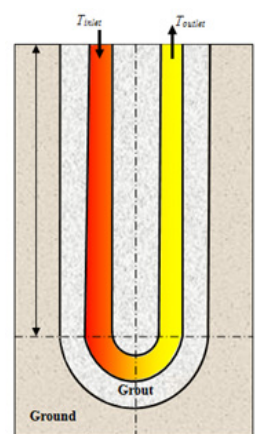

(a)

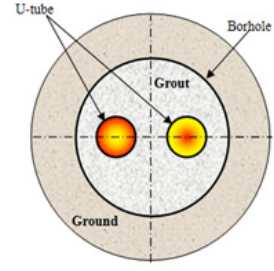

(b)
Fig. 6. Schematic diagram of a vertical U-tube ground heat exchanger: (a) longitudinal cross-section, (b) horizontal cross-section.

\section{B. Physical Parameters and Boundary Conditions}

The physical parameters are the same as that used by authors in [28] (see Tables I and II). Noting that in this simulation, the full model is used taking into account the thermal and dynamic effects and consequently other parameters have been added, such as, the fluid mass flow rate $(0.3 \mathrm{Kg} / \mathrm{s})$ and the temperature of the inlet fluid $\left(300^{\circ} \mathrm{K}\right)$. These parameters are taken from [29]. The details of the initial and boundary conditions are:

- The velocity is maximum at the center of the tube in the $\mathrm{z}$ direction.

- The upper surface is defined as an adiabatic wall.

- At the outer edge of the domain, a temperature condition has been imposed. The surface is also defined as a solid wall at a constant temperature of $283^{\circ} \mathrm{K}$, the groundwater flow was considered negligible.

\section{Mesh of the Model}

It is important to note that the definition of geometry and the way in which it is realized is the fundamental point of this work, since the vertical geothermal heat exchanger is built from several volumes that can be assembled to form the desired computational domain. The realized volumes are meshed, then recorded under the .dbs extension of Gambit. In this numerical 
simulation, a hybrid mesh with tetrahedron, hexahedron and wedge element was used as shown in Figure 7. It should be noted that this type of mesh is considered being more convenient for heat transfer analysis in GHE [20]. The Fluent software [30] was used for modeling, visualization and analysis of fluid flows and heat transfer using the finite volume method. The model resolution is performed in double precision.

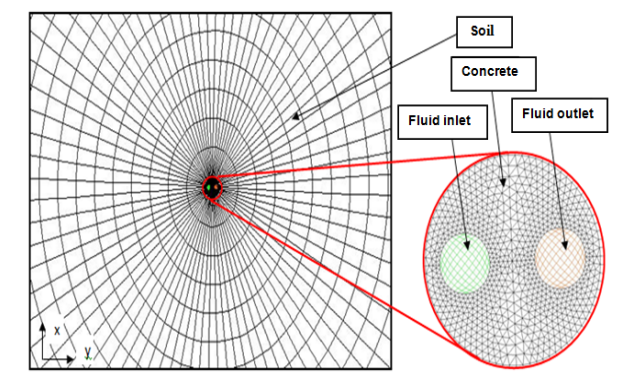

(a)

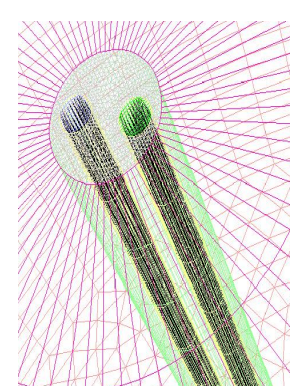

(b)

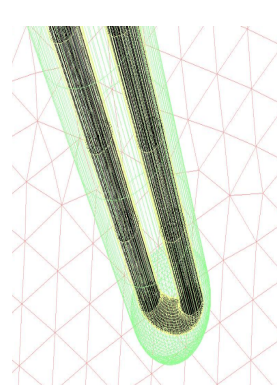

(c)
Fig. 7. Numerical mesh used for the studied model illustrating: (a) the various fields of calculation, (b) the upper and (b) lower parts of GHE.

\section{RESULTS AND DISCUSSION}

\section{A. Effect of U-tube Material}

In order to demonstrate the effect of the U-tube material on the evolution of the concrete wall temperature and the heat flow, five different materials were tested. The physical properties of these materials are shown in Table III. The obtained results for temperature and heat flow as a function of time are presented in Figures 8 and 9 respectively. The same variation trends were noticed for the five different materials. From Figure 8, we can see that the temperature increases rapidly at the beginning (until $t \sim 25 \mathrm{~h}$ ), afterwards a small change was observed. This is certainly due to the forced convection of the water to the tube, then the temperature increases slowly by conduction between the U-tube and the concrete grout. From Figure 9, it can be seen that the heat flux decreases very rapidly at the beginning, then a slight variation was noted afterwards for the five different types of U-tube material. From the results obtained, it can be noted that the maximum values of the temperature $\left(\mathrm{T}_{\max }=295^{\circ} \mathrm{K}\right)$ and flux $\left(\Phi_{\max }=87.54 \mathrm{~W} / \mathrm{m}^{2}\right)$ are obtained for the steel tube. While for polymers the best results are obtained for HDPE1 with a temperature $\mathrm{T}_{\max }=293.97^{\circ} \mathrm{K}$ and a flux $\Phi_{\max }=172.4 \mathrm{~W} / \mathrm{m}^{2}$. Knowing that the thermal storage depends on the physical properties of the ground but also on its moisture content and water migrations which have a significant impact on the system efficiency, then, to avoid problems of corrosion of the steels because of water particles that come into solution with these materials, it is recommended to use HDPE1 because it is a better heat carrier.

TABLE III. PHYSICAL PROPERTIES OF THE DIFFERENT MATERIALS STUDIED FOR THE U-TUBE.

\begin{tabular}{|c|c|c|c|}
\hline Tube materials & $\begin{array}{c}\text { Thermal } \\
\text { conductivity } \\
\left(\mathbf{W} / \mathbf{m}^{\circ} \mathbf{K}\right)\end{array}$ & $\begin{array}{c}\text { Density } \\
\left(\mathbf{K g} / \mathbf{m}^{\mathbf{3}}\right)\end{array}$ & $\begin{array}{c}\text { Specific heat } \\
\text { capacity } \\
\left(\mathbf{J} / \mathbf{K g}^{\circ} \mathbf{K}\right)\end{array}$ \\
\hline HDPE1 [28] & 0.48 & 1100 & 1465 \\
\hline HDPE2 [31] & 0.35 & 2300 & 920 \\
\hline Stainless steel [31] & 13.8 & 460 & 7817 \\
\hline Polyvinyl chloride [31] & 0.15 & 960 & 1380 \\
\hline
\end{tabular}

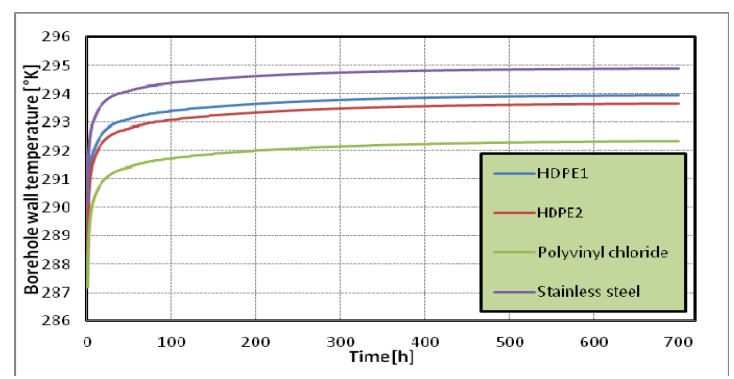

Fig. 8. Evolution of the concrete wall temperature of the geothermal heat exchanger as a function of time for five different materials ofU-tube.

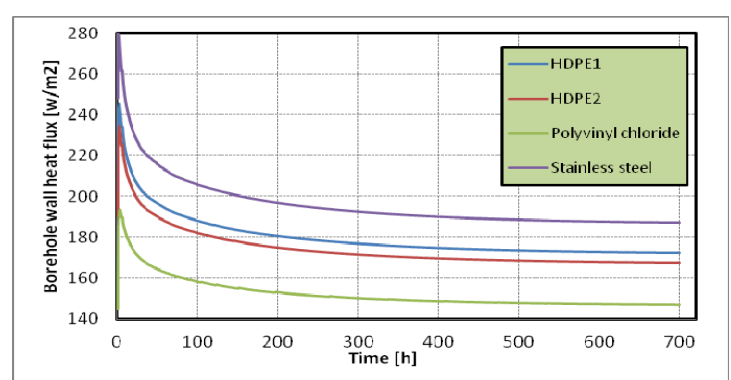

Fig. 9. Evolution of of heat flux of the geothermal heat exchanger concrete wall as a function of time for five different materials of U-tube.

\section{B. Effect of the Grout Material}

To study the effect of the grout material on the evolution of temperature and flux, four different types of concrete were tested. Table IV gives the values of thermal conductivity, density, and thermal capacity of these materials. To make a comparison of the temperature distribution, we have created a flat surface along the y-axis that divides the model of the geothermal heat exchanger in two parts for the four different types of concrete (Figure 10). On the basis of the numerical simulation coupled in fluid-solid 3D we presented the configurations of the distribution of the temperature for the four types of the concrete. Note that the latter is maximum in the middle of the tubes of the exchanger and decreases while moving away from the tube to the ground. By comparing the temperature distributions for the four types of concrete, it can 
be concluded that best results are obtained with concrete 2, while the worst ones are obtained with concrete 3 .

TABLE IV. PHYSICAL PROPERTIES OF THE DIFFERENT MATERIALS STUDIED FOR GROUTING CONCRETE.

\begin{tabular}{|c|c|c|c|}
\hline Grout materials & $\begin{array}{c}\text { Thermal } \\
\text { conductivity } \\
\left(\mathbf{W} / \mathbf{m}^{\circ} \mathbf{K}\right)\end{array}$ & $\begin{array}{c}\text { Density } \\
\left(\mathbf{K g} / \mathbf{m}^{\mathbf{3}} \mathbf{)}\right.\end{array}$ & $\begin{array}{c}\text { Specific heat } \\
\text { capacity } \\
\left(\mathbf{J} / \mathbf{K g} \mathbf{g}^{\circ} \mathbf{K}\right)\end{array}$ \\
\hline Concrete1 [28] & 1.3 & 2500 & 1561 \\
\hline Concrete2 [31] & 1.4 & 2210 & 750 \\
\hline $\begin{array}{c}\text { Concrete3 } \\
\text { (Silica sand) [32] }\end{array}$ & 0.6 & 1420 & 1197 \\
\hline $\begin{array}{c}\text { Concrete4 } \\
\text { (Sand } \\
\text { bentonite)[33] }\end{array}$ & 1 & 1500 & 1600 \\
\hline
\end{tabular}

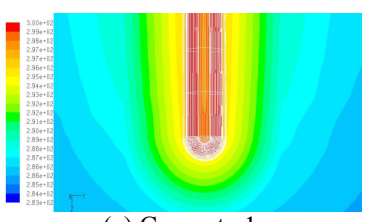

(a) Concrete 1

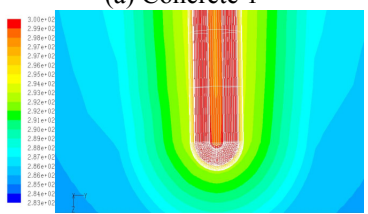

(c) Concrete 3

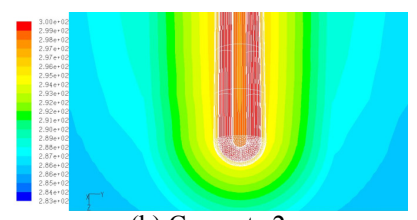

(b) Concrete 2
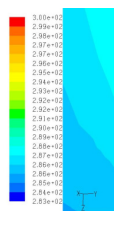

Fig. 10. Temperature distribution for the four types of concrete.

Figures 11 and 12 respectively show the evolutions of the temperature and heat flow of the concrete wall as a function of time during 700 hours of operation for four types of concrete using a U-tube in HDPE1. It should be noted that the main objective in this section is to determine the appropriate concrete with the material chosen for the pipe in HDPE1. By comparing the results obtained for the four types of concrete, it can be noted that the best thermal performance is obtained by concrete 2 . Indeed, the maximum values of the temperature and the flux for this type of concrete are respectively $294.2^{\circ} \mathrm{K}$ and $175.4 \mathrm{~W} / \mathrm{m}^{2}$. In addition, it can be noted that the results closest to those of concrete 2 are those of concrete 1 where the temperature is $94^{\circ} \mathrm{K}$ with a flux of $172.4 \mathrm{~W} / \mathrm{m}^{2}$. Concrete 3 performs poorly.

\section{Effect of the Soil Properties}

In this section we will focus on the choice of soil that allows us to obtain the best thermal performance from an energy storage point of view. To do this, six different types of soil will be tested. The thermal properties of these soils are presented in Table V. The temperature distributions in the Utube geothermal heat exchanger at the medial surfaces for each soil type are shown in Figure 13. It can be seen that there is a slight difference between the isovalue contours of the temperatures obtained for the six soil types. Best results are obtained by silty clayey sand (Figure13(f)). The evolution of the borehole wall temperature as a function of time is illustrated in Figure 14. All simulations were made with the optimal parameters obtained previously for the materials of $U$ tube and concrete. It can be seen that the heat transfer is highly significant in the case of clay sand where the maximum temperature is $297.47^{\circ} \mathrm{K}$ after $700 \mathrm{~h}$. A slight difference compared to the sand was noted where the maximum temperature of the latter is $297.39^{\circ} \mathrm{K}$, which means that both soil types have better heat preservation. On the other hand, the type of soil that produces a poor heat conservator is shale where the maximum temperature does not exceed $294.76^{\circ} \mathrm{K}$.

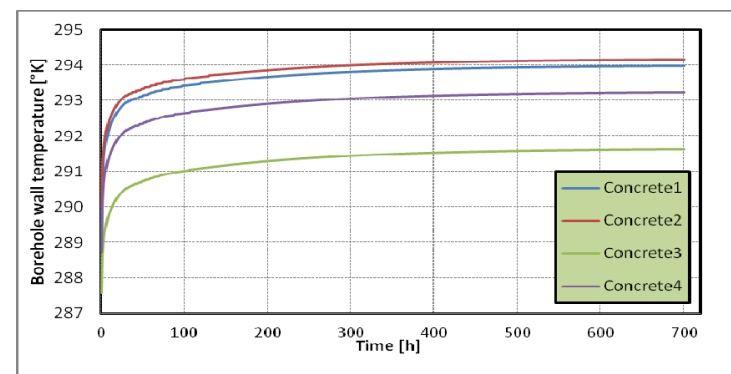

Fig. 11. Evolution of the concrete wall temperature of the geothermal heat exchanger as a function of time for four types of concrete.

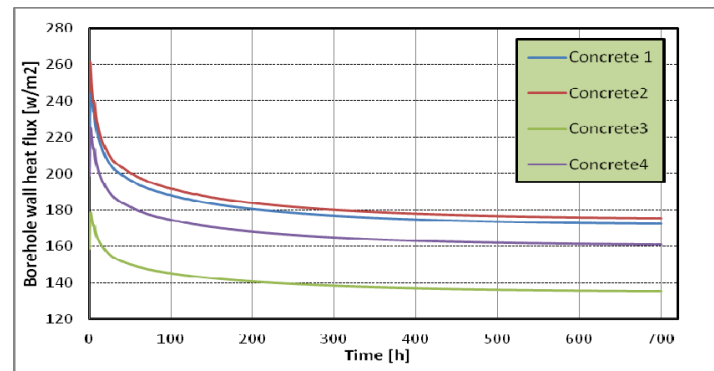

Fig. 12. Evolution of heat flux of the geothermal heat exchanger concrete wall as a function of time for four types of concrete.

TABLE V. PHYSICAL PROPERTIES OF THE STUDIED SOIL TYPES

\begin{tabular}{|c|c|c|c|}
\hline Soil materials & $\begin{array}{c}\text { Thermal } \\
\text { conductivity } \\
\left(\mathbf{W} / \mathbf{m}^{\circ} \mathbf{K}\right)\end{array}$ & $\begin{array}{c}\text { Density } \\
(\mathbf{K g} / \mathbf{m 3})\end{array}$ & $\begin{array}{c}\text { Specific heat } \\
\text { capacity } \\
\left(\mathbf{J} / \mathbf{K g}^{\circ} \mathbf{K}\right)\end{array}$ \\
\hline Clay [31] & 1.2 & 1700 & 1800 \\
\hline Sandy Clay [31] & 2.1 & 1960 & 1200 \\
\hline Sand [31] & 1.1 & 1510 & 1100 \\
\hline Silty clayey sand [34] & 1 & 1900 & 1500 \\
\hline Shale [34] & 2.9 & 2400 & 1200 \\
\hline Sandy slit [35] & 1.3 & 1847 & 1200 \\
\hline
\end{tabular}

\section{Effect of Flow Velocity}

To study the influence of the fluid (water) velocity on the thermal storage in the soil, five different velocities $U=\{0.173$, $0.273,0.373,0.473$ and $0.573 \mathrm{~m} / \mathrm{s}$ \} were tested using the previously selected materials for three components of the geothermal heat exchanger. The choice of these velocity values was based on [28], in which the velocity used was $0.373 \mathrm{~m} / \mathrm{s}$. A change of $\pm 0.1 \mathrm{~m} / \mathrm{s}$ has been added to this value. The results obtained for the evolution of the temperature of the concrete wall as a function of time for different water flow speeds are 
illustrated in Figure 15. It may be noted that as the flow velocity increases, the temperature rises, but this increase is not significant. Indeed, for a speed of $0.137 \mathrm{~m} / \mathrm{s}$ (minimum speed studied) the maximum temperature is $297.36^{\circ} \mathrm{K}$, while for a speed of $0.537 \mathrm{~m} / \mathrm{s}$ (maximum speed studied) the maximum temperature is $297.5^{\circ} \mathrm{K}$, meaning that a difference of $0.05 \%$ was found.

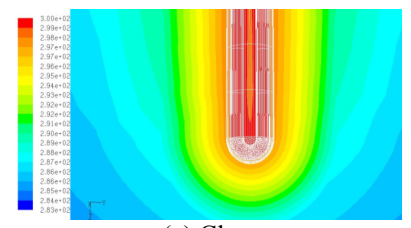

(a) Clay

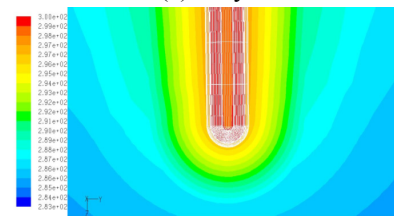

(c) Sandy clay

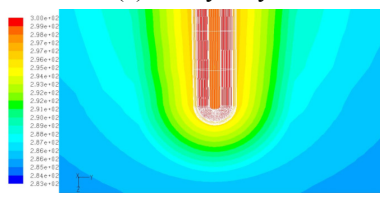

(e) Shale

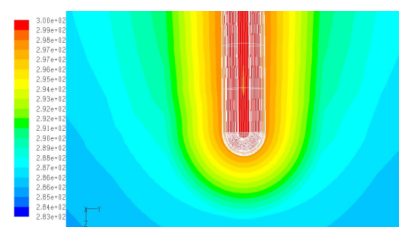

(b) Sand

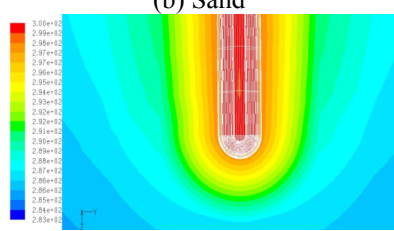

(d) Sand

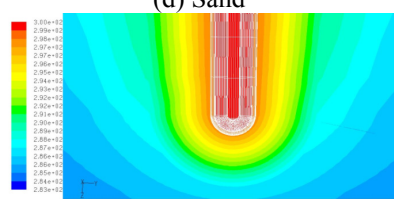

(f) Silty clayed send
Fig. 13. Contour plots of the temperature distribution for the six soil types.

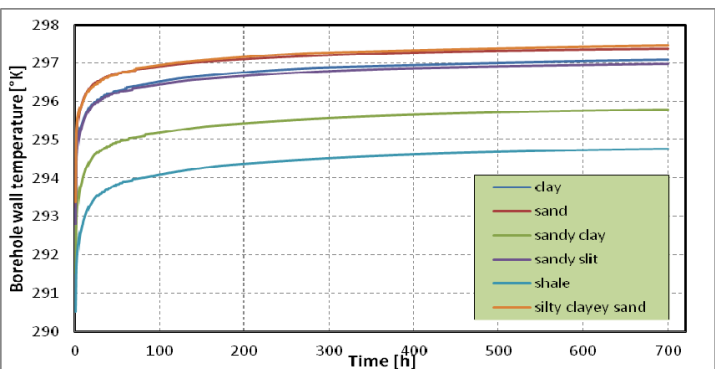

Fig. 14. Evolution of the concrete wall temperature of the geothermal heat exchanger as a function of time for different types of concrete.

Figure 16 shows the velocity vectors stained by the amplitude of the velocity. Increasing of the fluid velocity increases the intensity of the turbulence which causes the increase in forced convection heat transfer between the water and the U-tube wall. The heat that is released is transferred by conduction to the concrete wall which makes the temperature of the latter higher. It can be seen in Figure 13 that the velocity is maximum at the upper part at the beginning of the U-tube bend. The water is accelerated down until it reaches the elbow and then it slows down until it reaches its initial velocity of entry at the outlet of the U-tube. It should be noted that the magnitude of the velocity at the inlet and outlet of the tube is $0.373 \mathrm{~m} / \mathrm{s}$. The magnitude of the velocity at the entrance of the elbow reached $0.573 \mathrm{~m} / \mathrm{s}$.

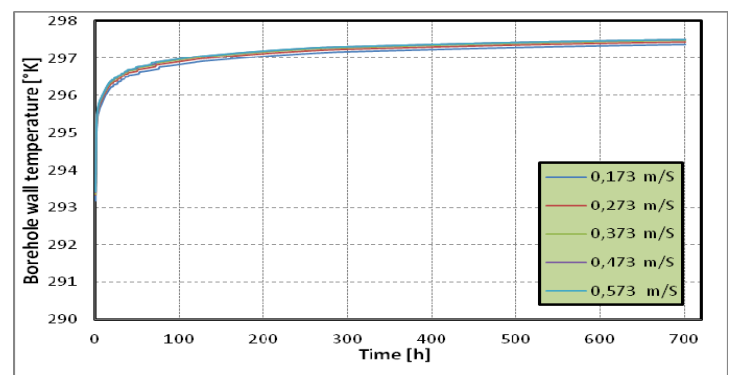

Fig. 15. Evolution of the borehole wall temperature for different water velocities.

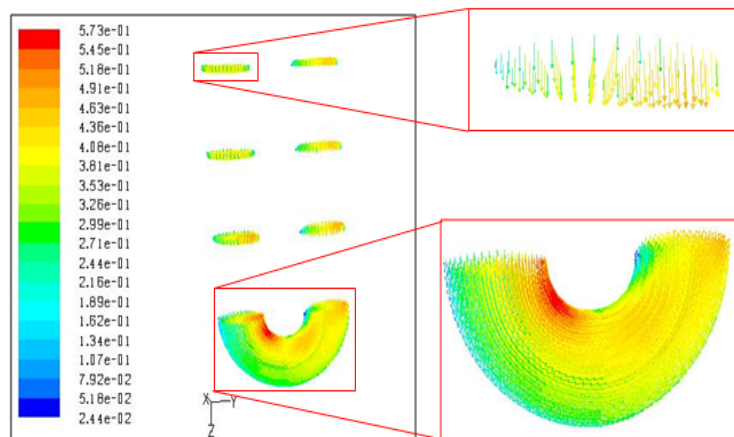

Fig. 16. Continuity and direction of the fluid flow.

\section{E. GHE Temperature Distribution in the Depth Direction}

After the optimization of the material properties, in this section, we focus to highlight the temperature distribution along the depth of the GHE. Figures 17 and 18 show the evolution of the temperature field inside the borehole along the radial direction of the GHE at different depths $(\mathrm{z}=0,2.5,4.5$ and $5.0 \mathrm{~m}$ ) for heat storage time of $700 \mathrm{~h}$. It can be seen that with increasing depth, the temperature in the radial direction gradually rises. Furthermore, a slight difference has been found between the temperature distribution for $2.5 \mathrm{~m}$ and $4.5 \mathrm{~m}$ or $5 \mathrm{~m}$. In addition, a symmetric distribution is noticed between the inlet branch part (to the left) and the outlet branch part (to the right) of the U-tube. This is because these illustrations were taken after the equilibrium state and the stability of the temperature distribution in the GHE (700h).

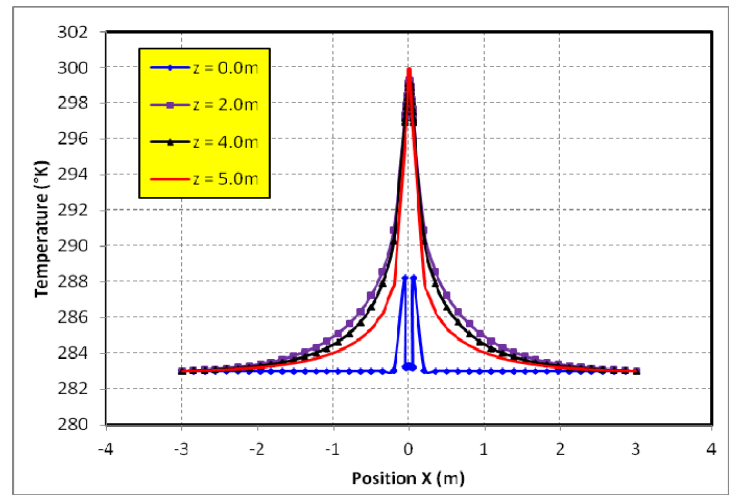

Fig. 17. Evolution of the temperature in the radial GHE direction 


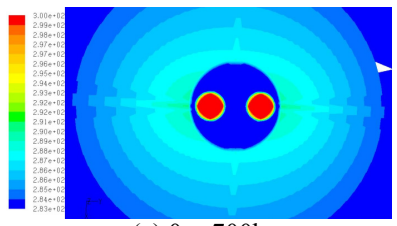

(a) $0 \mathrm{~m}-700 \mathrm{~h}$

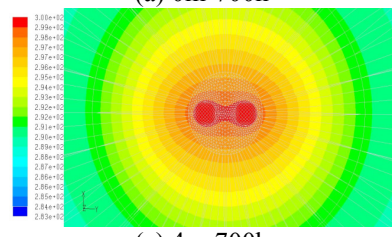

(c) $4 \mathrm{~m}-700 \mathrm{~h}$

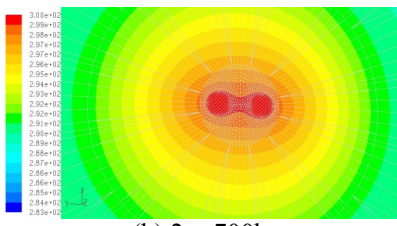

(b) $2 \mathrm{~m}-700 \mathrm{~h}$

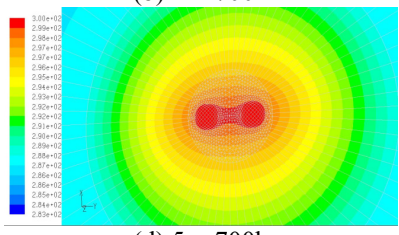

(d) $5 \mathrm{~m}-700 \mathrm{~h}$
Fig. 18. Contour plots of the temperature field in the radial direction of the GHE at different depths.

\section{CONCLUSION}

This study was dedicated to the optimization of solar energy storage systems based on a thermodynamic simulation of a U-tube vertical geothermal heat exchanger buried in concrete grout and soil. The 3D numerical simulation was based on forced convection and conduction in an unsteady flow. From the results presented in this numerical investigation, we can draw the following conclusions: (a) An acceptable agreement was found between the developed model validation results and those of the literature. (b) A slight influence of fluid flow velocity on energy conservation performance has been found. (c) To obtain the best performance for the developed geothermal heat exchanger model, it is recommended to use (i) a U-tube made of HDPE1 (thermal conductivity $0.48 \mathrm{~W} / \mathrm{m}^{\circ} \mathrm{K}$, density $1100 \mathrm{Kg} / \mathrm{m}^{3}$ and a mass thermal capacity of $14655 \mathrm{~J} / \mathrm{Kg}^{\circ} \mathrm{K}$ ), (ii) type 2 concrete (with high thermal conductivity and low specific heat capacity) for grout, (iii) clay sand as burial soil. The higher the soil thermal conductivity, the lower the temperature damping.

TABLE VI. NOMENCLATURE

\begin{tabular}{|c|c|}
\hline $\begin{array}{c}\mathbf{C}_{1 \varepsilon}, \mathbf{C}_{2 \varepsilon} \\
\mathbf{C}_{\mu}, \boldsymbol{\beta}_{\mathbf{i}}\end{array}$ & Constants used in the standard $\mathrm{k}-$ model \\
\hline $\mathrm{C}_{\mathrm{p}}$ & Specific heat $(\mathrm{J} / \mathrm{kgK})$ \\
\hline G & The turbulent flow production term \\
\hline $\mathbf{h}$ & Enthalpy $(\mathrm{J} / \mathrm{kg})$ \\
\hline $\mathbf{K}$ & Thermal conductivity $(\mathrm{W} / \mathrm{mK})$ \\
\hline $\mathbf{S}_{\kappa}, \mathbf{S}_{\varepsilon}, \mathbf{S}_{\varphi}$ & Sources terms \\
\hline $\mathbf{T}$ & Temperature $\left({ }^{\circ} \mathrm{K}\right)$ \\
\hline $\mathbf{P}$ & Static pressure \\
\hline $\mathbf{U}$ & Fluid velocity in the $\mathrm{x}$-direction $(\mathrm{m} / \mathrm{s})$ \\
\hline $\mathbf{V}$ & Fluid velocity in the $y$-direction $(\mathrm{m} / \mathrm{s})$ \\
\hline $\mathbf{W}$ & Fluid velocity in the $\mathrm{z}$-direction $(\mathrm{m} / \mathrm{s})$ \\
\hline $\mathbf{x}, \mathbf{y}, \mathbf{z}$ & Cartesian coordinates $(\mathrm{m})$ \\
\hline$\varepsilon$ & Dissipation rate of turbulence energy $\left(\mathrm{m}^{2} / \mathrm{s}\right)$ \\
\hline$\varphi$ & General dependant variable \\
\hline$\Gamma_{\varphi}$ & Diffusion coefficient \\
\hline $\mathbf{K}$ & Turbulent kinetic energy $\left(\mathrm{m}^{2} / \mathrm{s}^{2}\right)$ \\
\hline$\lambda$ & Coefficient of thermal conductivity \\
\hline$\mu$ & Dynamic viscosity $(\mathrm{Pa} \cdot \mathrm{s})$ \\
\hline$\mu_{\mathrm{t}}$ & Turbulent viscosity $(\mathrm{Pa} \cdot \mathrm{s})$ \\
\hline$\rho$ & Density $\left(\mathrm{kg} / \mathrm{m}^{3}\right)$ \\
\hline $\boldsymbol{\sigma}_{\varepsilon}$ & Prandtl number of $\varepsilon$ \\
\hline$\sigma_{\kappa}$ & Prandtl number of $\kappa$ \\
\hline
\end{tabular}

\section{REFERENCES}

[1] B. Sanner, C. Karytsas, D. Mendrinos, L. Rybach, "Current status of ground source heat pumps and underground thermal energy storage in Europe", Geothermics, Vol. 32, Vol. 4-6, pp. 579-588, 2003

[2] J. W. Lund, D. H. Freeston, T. L. Boyd, "Direct utilization of geothermal energy 2010 worldwide review", Geothermics, Vol. 40, No. 3, pp. 159-180, 2011

[3] T. Bandos, A. E. Montero Reguera, P. J. Fernandez de Cordoba Castella, J. F. Urchueguía Schölzel, "Urchueguia, Improving parameter estimates obtained from thermal response tests: effect of ambient air temperature variations", Geothermics, Vol. 40, No. 2, pp. 136-143, 2011

[4] A. D. Chiasson, Advances in modeling of ground-source heat pump systems, MSc Thesis, Oklahoma State University, 1999

[5] A. M. Omer, "Ground-source heat pumps systems and applications", Renewable \& Sustainable Energy Reviews, Vol. 12, No. 2, pp. 344-371, 2008

[6] C. Yavuzturk, J. D. Spitler, S. J. Rees, "A transient two-dimensional finite volume model for the simulation of vertical U-tube ground heat exchangers", ASHRAE Transactions, Vol. 105, No. 2, pp. 465-474, 1999

[7] L. R. Ingersoll, "Theory of Earth Heat Exchangers for the Heat Pump, Heat Conduction", American Society of Heating and Ventilating Engineers, Journal section, Heating, Piping, and Air Conditioning, 1950

[8] H. S. Carslaw, J. C. Jaeger, Conduction of Heat in Solids, Oxford University Press, 1959

[9] P. Eskilson, Thermal analysis of heat extraction boreholes, $\mathrm{PhD}$ Thesis, University of Lund, 1987

[10] S. P. Rottmayer, W. A. Bechman, J. W. Mitchell "Simulation of a single vertical U-tube ground heat exchanger in an infinite medium", ASHRAE Transactions, Vol. 103, pp. 651-659, 1997

[11] N. K. Muraya, D. L. O’Neal, W. M. Heffington, "Thermal interference of adjacent legs in vertical U-tube heat exchanger for a ground-coupled heat pump", ASHRAE Transactions,Vol. 102, No. 2, pp. 12-21, 1996

[12] J. A. Shonder, J. V. Beck, "Determining effective soil formation thermal properties from field data using parameter estimation technique", ASHRAE Transactions, Vol. 105, pp. 458-466, 1999

[13] C. K. Lee, H. N. Lam, "Computer simulation of borehole ground hea exchanger for geothermal heat pump systems", Renewable Energy, Vol. 33, No. 6, pp. 1286-1296, 2008

[14] D. Marcotte, P. Pasquier, "On the estimation of thermal resistance in borehole thermal conductivity test", Renewable Energy, Vol. 33, No. 11, pp. $2407-2415,2008$

[15] Z. J. Li, M. Y. Zheng, "Development of a numerical model for the simulation of vertical U-tube ground heat exchangers", Applied Thermal Engineering, Vol. 29, No. 5-6, pp. 920-924, 2009

[16] C. Yavuzturk, J. D. Spitler, "A short time step response factor model for vertical ground loop heat exchangers", ASHRAE Transactions, Vol. 105, No. 2, pp. 475-485, 1999

[17] J. Claesson, S. Javed, "An analytical method to calculate borehole fluid temperatures for time-scales from minutes to decades", ASHRAE Transactions, Vol. 117, No. 2, pp. 279-288, 2011

[18] L. Lamarche, S. Kajl, B. Beauchamp, "A review of methods to evaluate borehole thermal resistances in geothermal heat-pump systems", Geothermics, Vol. 39, No. 2, pp. 187-200, 2010

[19] D. Marcotte, P. Pasquier, F. Sherif, M. Bernier, "The importance of axia effects for borehole design of geothermal heat-pump systems", Renewable Energy, Vol. 35, No. 4, pp. 763-770, 2010

[20] B. Bouhacina, R. Saim, H. Benzenine, H. F. Oztop, “Analysis of thermal and dynamic comportment of a geothermal vertical U-tube heat exchanger", Energy and Buildings, Vol. 58, pp. 37-43, 2013

[21] L. Pu, D. Qi, K. Li, H. Tan, Y. Li, "Simulation study on the thermal performance of vertical U-tube heat exchangers for ground source heat pump system”, Applied Thermal Engineering, Vol. 79, pp. 202-213, 2015 
[22] C. Zhang, P. Chen, Y. Liu, S. Sun, D. Peng, “An improved evaluation method for thermal performance of borehole heat exchanger", Renewable Energy, Vol. 77, pp. 142-151, 2015

[23] W. Fujun (Ed.), The Dynamics Analysis of the Computational Fluid, Tsinghua University Press, 2004

[24] S. V. Patankar, Numerical Heat Transfer and Fluid Flow, Hemisphere, 1980

[25] P. Eskilson, J. Claesson, "Simulation model for thermally interacting heat extraction boreholes", Numerical Heat Transfer, Vol. 13, No. 2, pp. 149-165, 1988

[26] C. K. Lee, H. N. Lam, "Computer simulation of borehole ground heat exchangers for geothermal heat pump systems", Renewable Energy, Vol. 33, pp. 1289-1296, 2008

[27] H. Y. Zeng, N. R. Diao, Z. H. Fang, "A finite line-source model for boreholes in geothermal heat exchangers", Heat Transfer - Asian Research, Vol. 31, No. 7, pp. 558-567, 2002

[28] E. J. Kim, J. J. Roux, G. Rusaouen, F. Kuznik, "Numerical modeling of geothermal vertical heat exchangers for the short time analysis using the state model size reduction technique", Applied Thermal Engineering, Vol. 30, No. 6-7, pp. 706-714, 2010

[29] W. Yang, M. Shi, G. Liu, Z. Chen, "A two-region simulation model of vertical U-tube ground heat exchanger and its experimental verification", Applied Energy, Vol. 86, No. 10, pp. 2005-2012, 2009

[30] D. Fadla, Manuel de maillage sous Gambit et de simulation sous Fluent applications, Laboratoire d'énergétique et de mécanique de fluides interne ENSAM, CER de Paris, 2007

[31] Jalaluddin, A. Miyara . "Thermal performance investigation of several types of vertical ground heat exchangers with different operation mode", Applied Thermal Engineering, Vol. 33-34, pp. 167-174, 2012

[32] R. Al-Khoury, S. Focaccia, "A spectral model for transient heat flow in a double U-tube geothermal heat pump system”, Renewable Energy, Vol. 85 , pp. 195-205, 2016

[33] T. Y. Ozudogru, C. G. Olgun, A. Senol, "3D numerical modeling of vertical geothermal heat exchangers", Geothermics, Vol. 51, pp. 312324,2014

[34] T. Y. Ozudogru, O. Ghasemi-Fare, G. Olgun, P. Basu, "Numerical modeling of vertical geothermal heat exchanger using finite difference and finite element techniques", Geotechnical and Geological Engineering, Vol. 33, No. 2, pp. 291-306, 2015

[35] B. Bezyan, S. Porkhial, A. Aboui Mehrizi, "3-D simulation of heat transfer rate in geothermal pile-foundation heat exchangers with spiral pipe configuration", Applied Thermal Engineering, Vol. 87, pp. 655668,2015 